\title{
Bone mineral density is reduced in patients with Crohn's disease but not in patients with ulcerative colitis: a population based study
}

\author{
J Jahnsen, J A Falch, E Aadland, P Mowinckel
}

\begin{abstract}
Background-Patients with inflammatory bowel disease are at risk of developing metabolic bone disease.

Aims-To compare bone mineral density in patients with Crohn's disease with patients with ulcerative colitis and healthy subjects, and to evaluate possible risk factors for bone loss in inflammatory bowel disease.

Patients -60 patients with Crohn's disease, 60 with ulcerative colitis, and 60 healthy subjects were investigated. Each group consisted of 24 men and 36 women. Methods-Lumbar spine, femoral neck, and total body bone mineral density were measured by dual $x$ ray absorptiometry (DXA), and $Z$ scores were obtained by comparison with age and sex matched normal values.

Results-Mean $\mathrm{Z}$ scores were significantly lower in patients with Crohn's disease compared with patients with ulcerative colitis and healthy subjects. Patients with ulcerative colitis had bone mineral densities similar to healthy subjects. Use of corticosteroids, body mass index (BMI), and sex were significant predictor variables for bone mineral density in Crohn's disease. In ulcerative colitis only body mass index and sex were of significant importance. Disease localisation and small bowel resections had no influence on bone mineral density in patients with Crohn's disease.

Conclusions-Patients with Crohn's disease have reduced bone mineral density. Several factors are probably involved, but the reduction is associated with corticosteroid therapy. When studying skeletal effects of inflammatory bowel disease, patients with Crohn's disease and those with ulcerative colitis should be evaluated separately.

(Gut 1997; 40: 313-319)
\end{abstract}

Keywords: bone mineral density, inflammatory bowe disease, Crohn's disease, ulcerative colitis, osteoporosis.

Previous studies have shown that patients with inflammatory bowel disease have reduced bone mineral density in both cortical and trabecular bone. ${ }^{1-3}$ The reason for this is not clearly understood, but it is thought to be multifactorial. Possible causes include use of corticosteroids, disturbances of calcium homeo- stasis with a background of malabsorption and vitamin $\mathrm{D}$ deficiency, sex hormone deficiency, smoking habits, and the inflammatory process itself by releasing cytokines interacting with bone metabolism. However, most published data show no difference in bone mineral density between patients with Crohn's disease and those with ulcerative colitis. ${ }^{2}{ }^{4}$ In most studies few patients were investigated, and patients with Crohn's disease and ulcerative colitis were initially regarded as one group. We have performed a cross sectional population based study to compare bone mineral density of the lumbar spine, femoral neck, and total body skeleton in patients with Crohn's disease, patients with ulcerative colitis and healthy subjects, in addition to studying possible risk factors for low bone mineral density.

\section{Methods}

\section{Subjects}

The catchment area for Aker hospital is a defined geographical part of the city of Oslo with 130000 inhabitants, about $25 \%$ of the city's population. All patients with Crohn's disease or ulcerative colitis living in this area are seen in our department. Every known patient with Crohn's disease in this population was invited by letter to participate in the present study. Three patients were excluded; one due to drug addiction and two because of psychiatric disorders. Altogether 98 patients were invited and 61 (36 women and 24 men) accepted. One of these patients was further excluded because of ethnic origin (Vietnamese). Ninety eight patients with ulcerative colitis who matched the patients with Crohn's disease for age ( \pm 1 year) and sex, were also invited. Colectomised patients were excluded. Seventy five of the patients with ulcerative colitis accepted and 60 consecutively matching patients were included. Seven of the women in the Crohn's disease and ulcerative colitis groups were postmenopausal. The controls were comprised of 60 healthy subjects matched for sex and age ( \pm 1 year), who were randomly drawn from 385 normal, healthy persons comprising our Norwegian reference population for bone mass measurements. ${ }^{5}$ For the age-group 20-49 years, the normal reference persons were recruited from among hospital staff, medical students, and their friends. In the age group 50-79 years, they were recruited from among hospital staff, social centres for elderly people, a population 
TABLE I Clinical features of healthy subjects (HS), patients with ulcerative colitis (UC), and those with Crohn's disease (CD)

\begin{tabular}{lccc}
\hline & $H S$ & $U C$ & $C D$ \\
\hline Age (yr) (median (range)) & $36(21-75)$ & $38(21-75)$ & $36(21-75)$ \\
Sex (men/women) & $24 / 36$ & $24 / 36$ & $24 / 36$ \\
Post/premenopausal & $7 / 29$ & $7 / 29$ & $7 / 29$ \\
Weight (kg) (mean (SD)) & $71(13)$ & $75(17)$ & $68(12)$ \\
Height (cm) (mean (SD)) $\dagger$ & $174(9)$ & $172(11)$ & $171(9)$ \\
BMI (kg/m (mean (SD) $\ddagger_{\text {Total steroid dose (g) (median (range))\$ }}$ & $23 \cdot 4(3 \cdot 1)$ & $25 \cdot 2(5 \cdot 1)$ & $23 \cdot 3(4 \cdot 3)$ \\
& & $1 \cdot 8(0 \cdot 3-37)$ & $7 \cdot 2(1 \cdot 0-51)$ \\
\hline
\end{tabular}

${ }^{\star} \mathrm{p}=0.012$ UC $v \mathrm{CD} ; \mathrm{t}=0.044 \mathrm{HS} v \mathrm{CD} ; \neq \mathrm{p}=0.021 \mathrm{HS} v \mathrm{UC}$ and $\mathrm{p}=0.031 \mathrm{UC} v \mathrm{CD} ; \mathrm{p}<0.05$ received total dose of corticosteroids. based study on risk factors for osteoporosis (The European Vertebral Osteoporosis Study),${ }^{6}$ and a group of normal women who have been followed longitudinally since $1977 .^{7}$ None of the reference subjects had disease or used medication which could influence bone metabolism. Subjects who had sustained fractures of the upper femur, humerus, or forearm were also excluded.

A history of fractures was obtained. Body weight and height were measured without shoes and with light indoor clothing, and the body mass index (BMI) was calculated as weight $/$ height $^{2}\left(\mathrm{~kg} / \mathrm{m}^{2}\right)$. Table I shows further demographic and clinical data.

The diagnosis of inflammatory bowel disease was based on endoscopical, radiological, and histological examinations. Eleven $(18 \%)$ of the patients with ulcerative colitis had proctitis, 13 $(22 \%)$ proctosigmoiditis, eight $(13 \%)$ left sided colitis, and $28(47 \%)$ substantial or total colitis. Among the patients with Crohn's disease, $11(18 \%)$ had the disease located in the large bowel, $16(27 \%)$ in the small bowel, and 33 patients $(55 \%)$ had involvement of both small and large bowel. Small bowel resection had been performed at least once in 27 patients with Crohn's disease (45\%). The length of small bowel resected varied from 10 to $170 \mathrm{~cm}$, median $60 \mathrm{~cm}$. The median duration of inflammatory bowel disease in the Crohn's disease group was 10 (range 1-38) years and in the ulcerative colitis group seven (range $0 \cdot 5-32)$ years $(p<0 \cdot 05)$. Thirty four of the patients with Crohn's disease $(57 \%)$ were smokers, compared with $17(28 \%)$ of the patients with ulcerative colitis $(\mathrm{p}<0 \cdot 01)$. Forty three $(72 \%)$ of the patients with Crohn's disease and $28(47 \%)$ of the patients with ulcerative colitis had received systemic corticosteroids $(p<0.01$; Table I). The cumulative lifetime dose of corticosteroids, without considering the use of steroid enemas, was calculated for all patients based on medical records and interview, and it was higher in patients with Crohn's disease $(p<0.05)$ (Table I). At the time of the study 11 of the patients with Crohn's disease and five of the patients with ulcerative colitis were taking corticosteroids for maintenance treatment. In addition three patients with Crohn's disease were treated with azathioprine, and 29 patients with Crohn's disease and 40 with ulcerative colitis were treated with sulfasalazine or 5-ASA preparations. Most patients were in clinical remission. Ten of the patients with Crohn's disease and three of those with ulcerative colitis were supplemented with vitamin $\mathrm{D}$, or calcium, or both. Two patients with Crohn's disease used oral contraceptives. In the ulcerative colitis group three patients used oral contraceptives and two postmenopausal women received hormone replacement therapy. One of the patients with Crohn's disease had primary $\Omega$ sclerosing cholangitis with slightly raised transaminases and normal bilirubin. Two patients $\underset{\vec{S}}{\overrightarrow{\mathrm{S}}}$ with Crohn's disease (one man and one $\overline{0}$ woman) had chronic pyelonephritis with slightly 음 raised serum creatinine (185 and $159 \mu \mathrm{mol} / \mathrm{l}$ क respectively; normal range 55-125 $\mu \mathrm{mol} / \mathrm{l})$. $\stackrel{\odot}{\circ}$ Three patients with Crohn's disease had anky- क losing spondylitis and another three had $\vec{\circ}$ seronegative polyarthritis. Two patients with ulcerative colitis had been treated for hypo- $\vec{\omega}$ thyroiditis for several years, and were biochemically and clinically euthyroid.

\section{Bone density measurement}

Bone mineral density of lumbar L2-L4 $\vec{\omega}$ vertebrae in the anterioposterior projection, $\stackrel{\text { 의 }}{\rightarrow}$ femoral neck, and total body skeleton were $\vec{z}$ determined by dual $x$ ray absorptiometry (DXA; Lunar DPX-1, Madison, USA). As $\frac{\rho}{\sigma}$ bone mass is sex and age specific, the $\vec{\varphi}$ individual values were converted to $\mathrm{Z}$ scores, indicating the number of standard deviations from the normal sex specific and age specific mean value derived from the Norwegian reference population. ${ }^{5}$ This approach permits the pooling of the results from each group $\mathbb{D}$ studied. The coefficients of variation $(\mathrm{CV} \%) \stackrel{2}{\Rightarrow}$ for DXA in our hands were $1.0 \%$ for the lumbar spine (L2-L4), $2 \cdot 5 \%$ for the femoral neck, and $0.7 \%$ for the total body.

\section{Statistical analysis}

Statistical differences were evaluated by Student's $t$ test and $\chi^{2}$ or analysis of variance $\frac{O}{3}$ (ANOVA) as appropriate. Pearson's correlation coefficients were calculated for the continuous variables. To evaluate whether the $\frac{}{0}$ significant differences found between the three groups were present when correcting for N background variables, an analysis of covariancen (ANCOVA) was performed with backgroundN variables as covariates. According to previous knowledge about possible risk factors, the following background variables were chosen: $\frac{\bar{\Phi}}{\mathrm{C}}$ use of corticosteroids, smoking habits, sex, $\stackrel{?}{+}$ BMI, and duration of illness. To find predictor variables for the bone mineral density deficiencies, regression analyses were carried $\stackrel{\mathbb{\rho}}{\stackrel{9}{ }}$ out with the above mentioned covariates as $\Omega$ independent variables. For the ANCOVA and regression analyses, the assumptions of theo models were checked by the use of Jack-knifeo residuals, Cook's d and Mallow's $C_{p}$. For the ANCOVA the assumption of parallel slopes? was checked. p Values $<0.05$ were considered to be significant.

\section{Results}

Bone mineral density in patients with Crohn's disease were significantly reduced at all 
TABLE II Bone mineral density (BMD) measurements $\left(\mathrm{g} / \mathrm{cm}^{2}\right)$, mean (CI), in healthy subjects (HS), patients with ulcerative colitis (UC) and those with Crohn's disease (CD)

\begin{tabular}{|c|c|c|c|c|}
\hline & $\begin{array}{l}H S \\
(n=60) \\
\text { Mean }(95 \% \text { CI })\end{array}$ & $\begin{array}{l}U C \\
(n=60) \\
\text { Mean }(95 \% C I)\end{array}$ & $\begin{array}{l}C D \\
(n=60) \\
\text { Mean }(95 \% C I)\end{array}$ & $\begin{array}{l}p \text { Value } \\
C D \mathrm{v} \\
H S \text { and } U C\end{array}$ \\
\hline $\begin{array}{l}\text { Lumbar spine } \\
\text { Femoral neck } \\
\text { Total body }\end{array}$ & $\begin{array}{l}1.23(1.18 \text { to } 1.27) \\
0.98(0.94 \text { to } 1.03) \\
1.19(1.16 \text { to } 1.22)\end{array}$ & $\begin{array}{l}1.22(1.18 \text { to } 1.26) \\
1.00(0.96 \text { to } 1.03) \\
1.19(1.16 \text { to } 1.21)\end{array}$ & $\begin{array}{l}1.14(1.10 \text { to } 1.19) \\
0.91(0.87 \text { to } 0.96) \\
1.13(1.10 \text { to } 1.15)\end{array}$ & $\begin{array}{l}<0.05 \\
<0.05 \\
<0.005\end{array}$ \\
\hline
\end{tabular}

measured sites compared with patients with ulcerative colitis and healthy subjects (Table II). Figure 1 shows the individual $\mathrm{Z}$ scores in the three groups for the L2-L4 vertebrae. Figure 2 shows these for the femoral neck and Fig 3 for the total body. A significant difference in $Z$ scores was found between patients with Crohn's disease and patients with ulcerative colitis (lumbar spine $(p=0.018)$, femoral neck $(p=0 \cdot 0004)$, total body skeleton $(p=0 \cdot 014))$, and between patients with Crohn's disease and healthy subjects (lumbar spine $(p=0.028)$, femoral neck $(p=0.012)$, total body skeleton $(p=0.0001))$. No significant differneces were found between patients with ulcerative colitis and healthy subjects. $Z$ scores of total body skeleton were significantly correlated with femoral neck and lumbar spine $\mathrm{Z}$ scores in all three groups $(r=0.63-0.73, \mathrm{p}=0.001)$.

The extension and location of the inflammatory process had no significant influence on bone mineral density in patients with Crohn's disease nor patients with ulcerative colitis. Furthermore, there were no correlations between disease duration and bone mineral density in either group. In patients with
Crohn's disease small bowel resections had no influence on bone mineral density.

Treatment with corticosteroids was associated with significantly reduced bone mineral density in patients with Crohn's disease but this pattern was not found in patients with ulcerative colitis (Table III). Furthermore, the total lifetime corticosteroid dose correlated significantly with lumbar spine $(r=-0.313$, $\mathrm{p}=0.018)$ and total body skeleton $(r-0.421$, $\mathrm{p}=0.0008$ ) bone mineral density $\mathrm{Z}$ score in Crohn's disease (Fig 4), but not in patients with ulcerative colitis. Bone mineral density in patients with Crohn's disease not treated with corticosteroids was similar to that found in patients with ulcerative colitis and healthy subjects.

Significantly more patients with Crohn's disease than patients with ulcerative colitis were smokers $(p<0 \cdot 01)$, but there were no differences in bone mineral density between smokers and non-smokers within the two groups.

In the two patient groups studied, men had lower $\mathrm{Z}$ scores than women. There were significant differences in body weight $(p<0.001)$ and height $(p<0.001)$ between the sexes, but no differences in body mass index. The number of male and female patients who had received corticosteroids was similar in both groups, but the mean total dose received by men was higher than in women $(15 \mathrm{~g} \mathrm{v} 9 \mathrm{~g}$ in Crohn's disease and $9 \mathrm{~g} v 3 \mathrm{~g}$ in ulcerative colitis; NS). For all other variables examined, there was no significant difference between the sexes in patients with Crohn's disease and

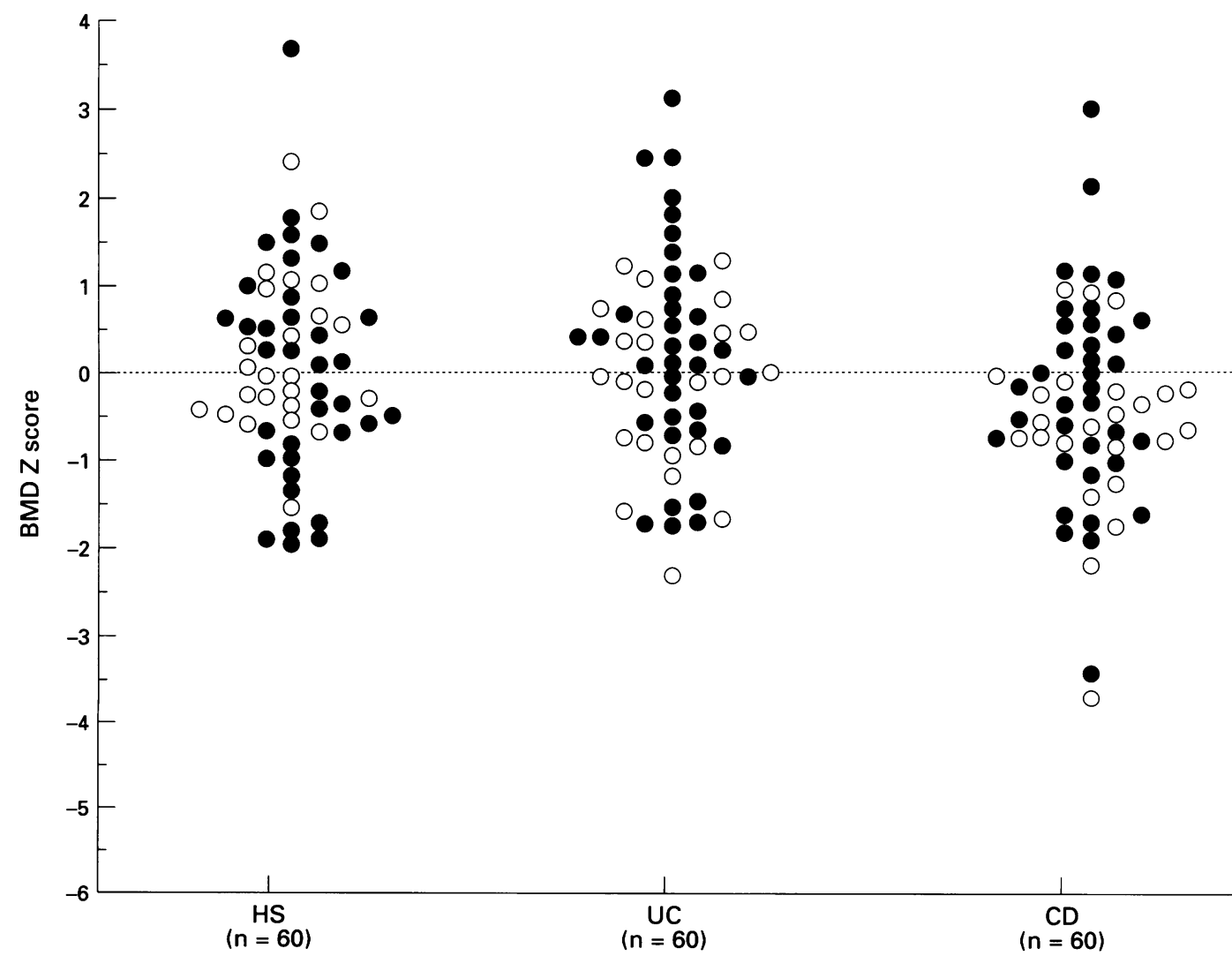

Figure 1: Bone mineral density (BMD) of the lumbar spine (L2-L4) in healthy subjects (HS), patients with ulcerative colitis (UC), and those with Crohn's disease (CD). The BMD measurements are given as $Z$ scores. $\bigcirc$ Females, $\bigcirc$ males. 
patients with ulcerative colitis. In the healthy subjects group, there were no differences in $\mathrm{Z}$ scores between men and women.
Comparison between male patients with Crohn's disease and male patients with ulcerative colitis disclosed differences in $\mathrm{Z}$ scores

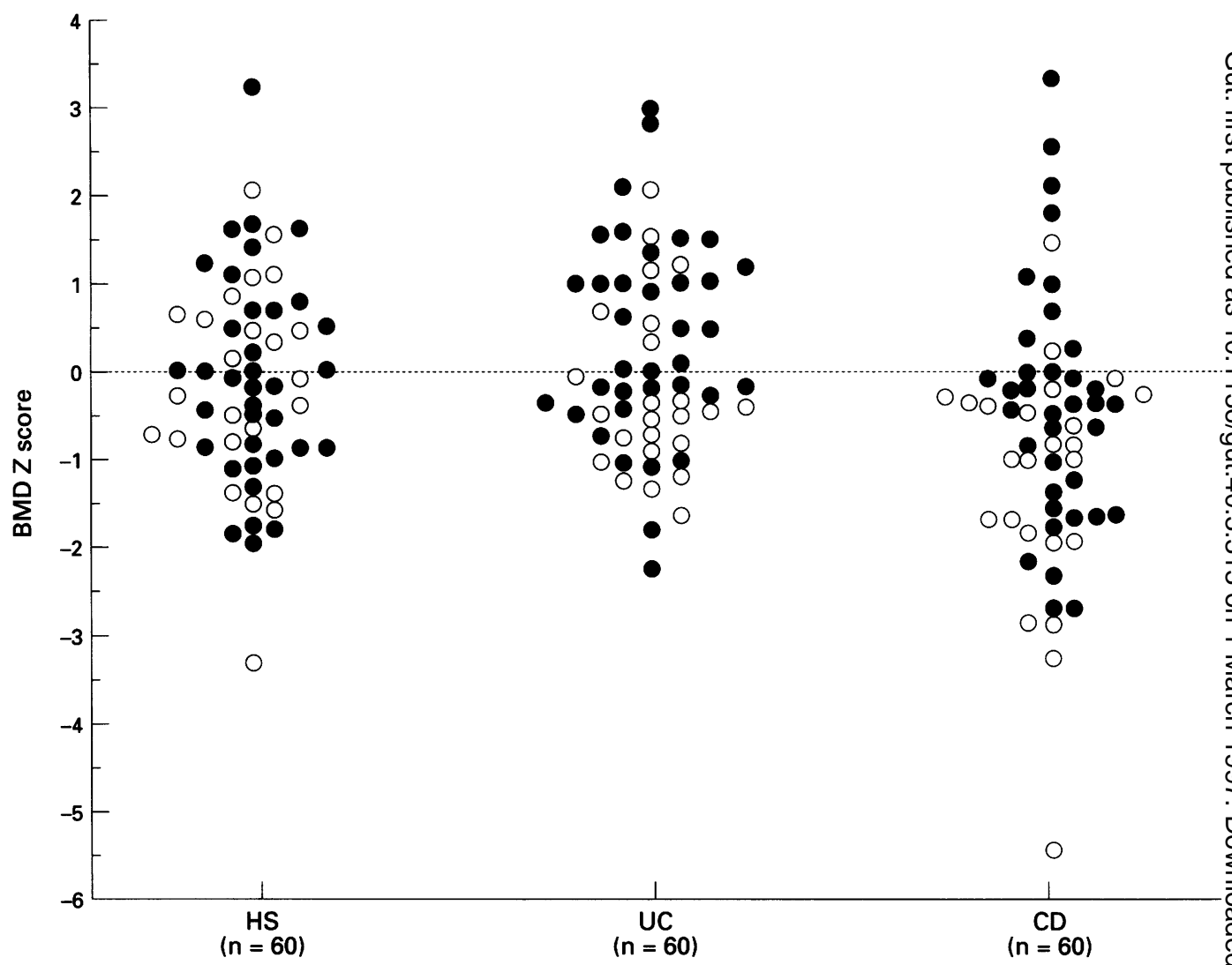

Figure 2: Bone mineral density (BMD) of the femoral neck in healthy subjects (HS), patients with ulcerative colitis (UC) and those with Crohn's disease (CD). The BMD measurements are given as $Z$ scores. Females, $\bigcirc$ males.

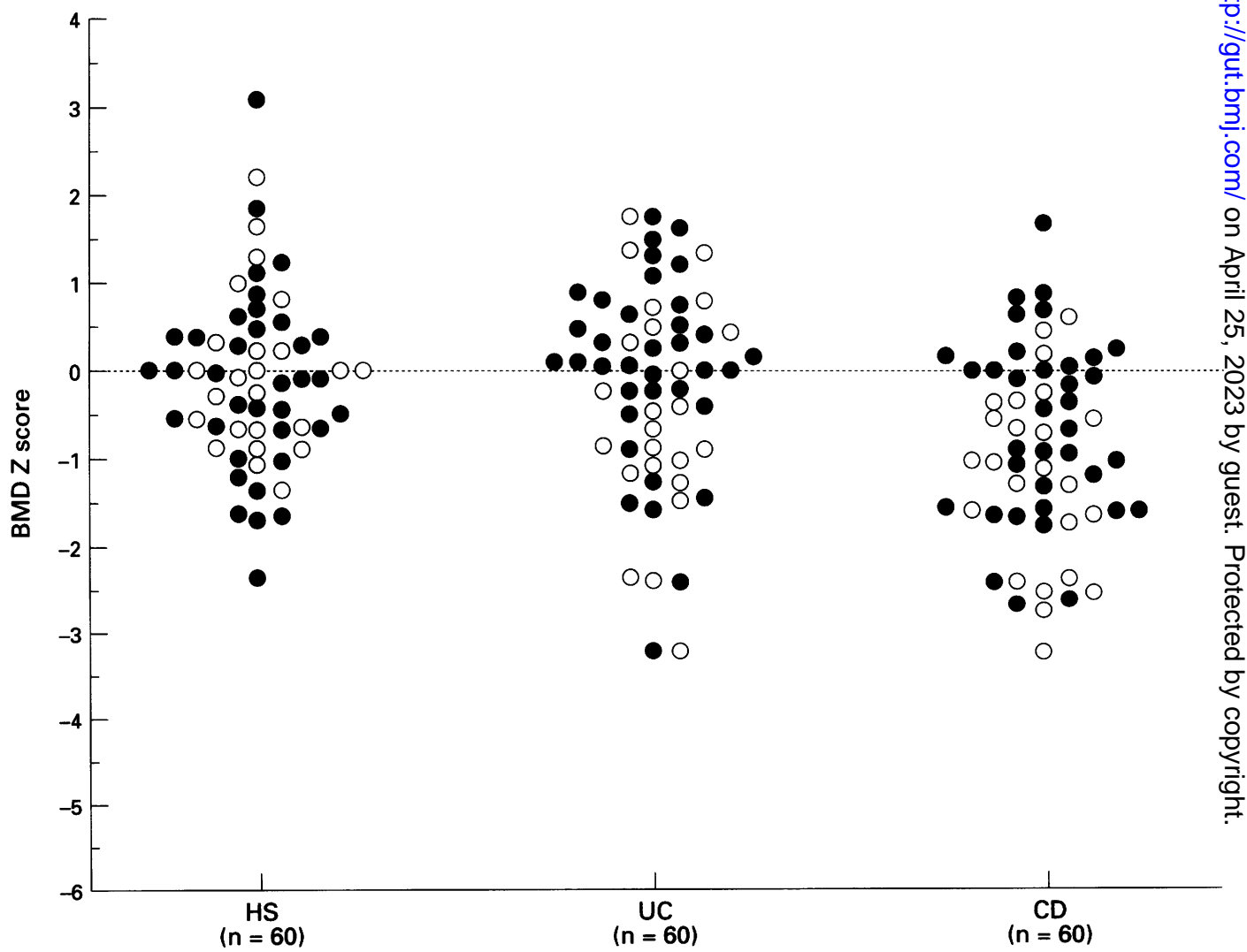

Figure 3: Bone mineral density (BMD) of the total body skeleton in healthy subjects (HS), patients with ulcerative colitis (UC) and those with Crohn's disease (CD). The BMD measurements are given as $Z$ scores. $O$ Females, $\bigcirc$ males. 
TABLE II Bone mineral density (BMD) expressed as $Z$ scores (mean (95\% CI)) in patients with ulcerative colitis (UC) and Crohn's disease (CD) with and without corticosteroid treatment

\begin{tabular}{|c|c|c|c|c|c|}
\hline & \multicolumn{2}{|l|}{$U C$} & \multicolumn{2}{|l|}{$C D$} & \multirow{2}{*}{$\begin{array}{l}p \text { Values } \\
\text { for } C D\end{array}$} \\
\hline & Steroids $+(n=28)$ & Steroids- $(n=32)$ & Steroids $+(n=43)$ & Steroids $-(n=17)$ & \\
\hline $\begin{array}{l}\text { Lumbar spine } \\
\text { Femoral neck } \\
\text { Total body }\end{array}$ & $\begin{array}{r}0.29(-0.18 \text { to } 0.77) \\
0.16(-0.34 \text { to } 0.66) \\
-0.07(-0.54 \text { to } 0.40)\end{array}$ & $\begin{array}{r}0.06(-0.44 \text { to } 0.32) \\
0.09(-0.27 \text { to } 0.45) \\
-0.27(-0.69 \text { to } 0.14)\end{array}$ & $\begin{array}{l}-0.52(-0.88 \text { to }-0.17) \\
-0.97(-1.41 \text { to }-0.53) \\
-1.15(-1.47 \text { to }-0.82)\end{array}$ & $\begin{array}{l}-0.07(-0.63 \text { to } 0.49) \\
-0.17(-0.89 \text { to } 0.55) \\
-0.10(-0.48 \text { to } 0.28)\end{array}$ & $\begin{array}{l}\text { NS } \\
0 \cdot 05 \\
0 \cdot 0004\end{array}$ \\
\hline
\end{tabular}

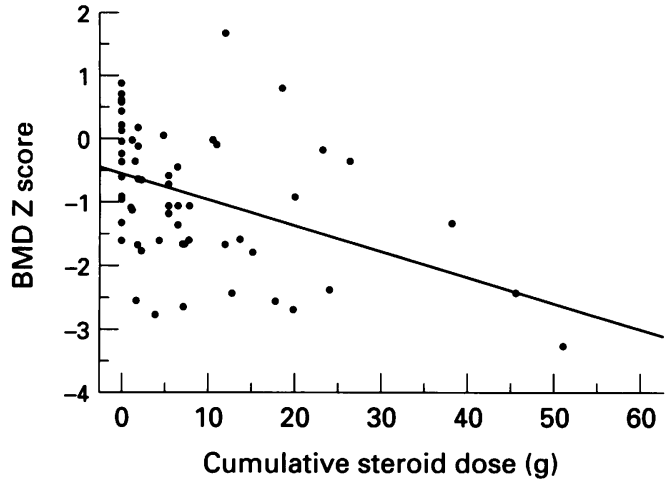

Figure 4: Correlation between bone mineral density (BMD) of the total body skeleton in patients with Crohn's disease and the total lifetime dose of corticosteroids, $(r=-0.421$, $p<0.001)$. The BMD measurements are given as $Z$ scores.

(lumbar spine: $-0.65 \quad v-0.15 \quad(\mathrm{p}=0.085)$, femoral neck: $-1.25 v-0.25(\mathrm{p}=0.007)$, total body skeleton: $-1.19 v-0.46 \quad(p=0.034))$. Similar differences were also found between female patients with Crohn's disease and female patients with ulcerative colitis (lumbar spine: $-0.23 v 0.28(\mathrm{p}=0.087)$, femoral neck: $-0.41 v 0.37(\mathrm{p}=0.013)$, total body skeleton: $-0.62 v 0.02(p=0.014))$. Seven women in both groups were postmenopausal and there was no difference in bone mineral density at any of the measured sites between premenopausal and postmenopausal women among either patients with Crohn's disease or patients with ulcerative colitis.

Twenty seven per cent (32/120) of our patients with inflammatory bowel disease have had at least one fracture. All radiological examinations were performed before the study inclusion and only in patients with clinical symptoms. Lateral radiographs of the lumbar and dorsal spine were used to ascertain vertebral deformity. Table IV shows the numbers and locations of the fractures. There were no differences between Crohn's disease and ulcerative colitis patients. In both groups the total body $\mathrm{Z}$ score was significantly lower in patients who had sustained fractures compared with those who had not $(-1.47 v$

TABLE IV Number of fractures and their locations in patients with ulcerative colitis (UC) and Crohn's disease (CD)

\begin{tabular}{lcc}
\hline & $U C(n=16)$ & $C D(n=16)$ \\
\hline Arm & 8 & 8 \\
Leg & 6 & 5 \\
Spine & 1 & 6 \\
Other locations & 3 & 21 \\
Total & 18 & 21 \\
\hline
\end{tabular}

$-0.62(p=0.006)$ in Crohn's disease and -0.73 $v 0.03(\mathrm{p}=0.026)$ in ulcerative colitis). The differences were not significant at the lumbar spine or the femoral neck level. Furthermore in patients with Crohn's disease, there was a significant difference in cumulative dose of corticosteroids between patients with and without previous fractures (14 $\mathrm{g} v 6 \mathrm{~g})$ $(p=0.009)$. A significant difference was not found in patients with ulcerative colitis $(4 \mathrm{~g} v$ $2 \mathrm{~g}$ ). Two patients with Crohn's disease (one man aged 26 years and a woman aged 66 years) had typically osteoporotic vertebral crush fractures. Both had low bone mineral density and had received total lifetime corticosteroid doses of 51 and $20 \mathrm{~g}$ respectively.

With bone mineral density as the dependent variable, the three groups were compared by ANCOVA. Sex, age, body mass index, and body weight were chosen as independent variables. For $Z$ score at the lumbar spine, sex was the only significant predictor variable $(p<0.01$; females had increased $Z$ score). At the femoral neck sex $(p=0.001)$ and body mass index $(p=0.02)$ were significant. For total body bone mineral density sex $(p=0.001)$ and body mass index $(p=0.01)$ were of significance (increasing $\mathrm{Z}$ score follows increasing body mass index). When comparing the two patient groups the following variables were used: use of corticosteroids, smoking habits, sex, body weight, body mass index, duration of disease, and intestinal resections. After adjusting for all of the variables listed there were still significant differences in bone density $\mathrm{Z}$ scores between patients with Crohn's disease and patients with ulcerative colitis; lumbar spine $(p=0.025)$, femoral neck $(p=0.014)$, and total body $(p=0.030)$. Within the Crohn's disease group, body mass index and the use of corticosteroids were the major factors predicting bone density, with increasing dose of steroids giving reduced bone density $Z$ scores (Fig 4). Within the ulcerative colitis group body mass index was the only variable of significant importance, $(p<0.01)$.

\section{Discussion}

In this cross sectional population based study, we found that patients with Crohn's disease had significantly reduced bone mineral density compared with patients with ulcerative colitis and healthy subjects at all measured sites. There were no differences in bone mineral density between the last two groups. Use of corticosteroids was associated with low bone mineral density in Crohn's disease but not in ulcerative colitis. Several previous studies have 
shown that patients with inflammatory bowel disease have reduced bone mineral density. ${ }^{8-10}$ Only one study showed a difference between patients with Crohn's disease and ulcerative colitis, and concluded that low bone mineral density is a feature in Crohn's disease and not in ulcerative colitis at the time of diagnosis. ${ }^{11}$ Our data also confirmed this pattern in patients with longstanding inflammatory bowel disease.

Although patients with inflammatory bowel disease are at risk of developing osteoporosis, a great variation in the prevalence of low bone mineral density has previously been found. ${ }^{10}$ One possible explanation for this could be the selection of patients. We assume that some other studies have included more severe cases of inflammatory bowel disease. This could also explain the fact that those studies have failed to show a difference in bone mineral density between patients with Crohn's disease and those with ulcerative colitis. In our study $60 \%$ of the patients with Crohn's disease in our catchment area were included, and were compared with a randomly selected age and sex matched group of patients with ulcerative colitis from the same population. We therefore anticipate that our results are representative for the bone mineral density status in patients with inflammatory bowel disease.

The adverse effect of corticosteroids on bone is well known, although the mechanism is not fully understood. ${ }^{12}{ }^{13}$ Both cortical and trabecular sites are affected. However, assessments of trabecular bone density show greater percentage loss. ${ }^{14}$ Rapid bone loss occurs initially with rates approaching $5 \%-20 \%$ in the first year, and increased rates persist for as long as corticosteroid treatment is given. ${ }^{15} 16$ Previous longitudinal studies in inflammatory bowel disease have failed to show any correlation between the rate of bone loss and the use of corticosteroids. ${ }^{17} 18$ In our study there was inverse correlation between total dose of corticosteroids and bone mineral density in Crohn's disease but not in ulcerative colitis. However, the calculated total dose of corticosteroids was significantly higher in the Crohn's disease group. It might be speculated whether a certain threshold dose of corticosteroids has to be exceeded before damage to the skeleton occurs, but this is controversial. Previous reports indicate that even low doses of corticosteroids may have a deleterious effect on bone. ${ }^{1920}$ However, the use of corticosteroids and total lifetime dosage is an expression of disease activity and severity, which could explain the finding that corticosteroids were associated with reduced bone mineral density in patients with Crohn's disease and not in patients with ulcerative colitis. Crohn's disease is generally regarded to be a more severe disease than ulcerative colitis, needing more corticosteroids for the control of disease. In patients with Crohn's disease who had received corticosteroids, total body bone mass, which comprised $80 \%$ cortical and $20 \%$ trabecular bone, showed a significant reduction. This was not found in lumbar spine bone mineral density, which mainly represents trabecular bone. This suggests that factors other than corticosteroids might be of importance for the reduction in bone mass. After adjusting for all recorded variables that may play a part in bone loss, there were still significant differences in bone density $\mathrm{Z}$ scores between patients with Crohn's disease and patients with ulcerative colitis, indicating that factors related to the diagnosis are of importance.

Several mechanisms are probably involved in $\overline{0}$ the negative impact of inflammatory bowel 흘 disease on bone mass. Generation of inflam- $\frac{\bar{\omega}}{7}$ matory mediators might cause an imbalance in $\stackrel{\mathbb{\Omega}}{\Omega}$ the bone remodelling cycle. In vitro studies have shown that several cytokines (interleukin- $\vec{\circ}$ 1 , interleukin-6, and tumour necrosis factor) act on both bone resorbing and bone forming $\vec{\omega}$ cells. ${ }^{21}$ Increased levels of markers for osteoclast activity in patients with inflammatory bowel disease have been found, and this $\overrightarrow{0}$ excessive activity could be due to cytokines $\omega$ released from the diseased intestine. ${ }^{22}$

The malabsorption which can accompany ${ }_{\bar{\omega}}$ inflammatory bowel disease has been suggested $\stackrel{5}{\rightarrow}$ to be an important determinant of bone $\vec{z}$ loss. ${ }^{2324}$ This theory was not supported by our findings as patients with Crohn's disease with $\stackrel{5}{5}$ colonic disease had bone mineral density $\vec{\varphi}$ similar to those with involvement of the small bowel. Furthermore, there were no differences between patients with Crohn's disease with or without small bowel resection. In addition, no correlations between the length of small bowel resected and bone mineral disease were found. $\stackrel{D}{\square}$ Also in the ulcerative colitis group there was no $\underset{\vec{O}}{\overrightarrow{2}}$ influence of disease location and extension on $\frac{0}{3}$ bone mineral disease.

Body mass index can be used as an indicator of the nutritional status, and has been shown to be significantly correlated with bone mineral density. ${ }^{25} 26$ The lower body mass index $\frac{5}{3}$ found in patients with Crohn's disease might therefore contribute to the differences in bone $\frac{0}{3}$ mineral disease found in patients with ulcer- 0 ative colitis and Crohn's disease in our study. 을 In the ANCOVA, body mass index was a major $\frac{D}{0}$ predictor for bone mineral density in all three groups studied.

In our study female patients had higher $\mathrm{Z} N$ scores than male patients in both inflammatory bowel disease groups. Although not significant, there was a difference in the total corticosteroid dose used between the sexes. This could be of $\frac{}{\Phi}$ importance as there is some evidence that men $\stackrel{\infty}{\rightarrow}$ receiving glucocorticoides lose bone more $\frac{T}{T}$ rapidly than women. ${ }^{27}$ Differences in all other $\frac{\vec{D}}{\mathbb{D}}$ variables recorded were negligible. In a pre- $\stackrel{\oplus}{\oplus}$ vious study, the use of corticosteroids was $\mathbb{Q}$ significantly associated with diminished bone mineral density in female patients and not 8 in male patients with inflammatory bowelo disease, and the authors suggested that female patients were probably more sensitive to corticosteroids. ${ }^{4}$

Sex hormone deficiency is an important pathogenetic factor contributing to low bone mineral density and hormone replacement therapy also prevents bone loss in patients with inflammatory bowel disease. ${ }^{28}$ In our study only seven of the female patients in each group 
were postmenopausal. This probably explains the fact that menstrual status had no significant influence on bone mineral density in our patients.

As reduced bone mineral density is a well documented risk factor for fractures, ${ }^{29-31}$ most studies have concentrated on such measurements. However, fractures are the major clinical end point of interest to the patients. One quarter of our patients with inflammatory bowel disease reported at least one fracture, which seems to be a high prevalence rate. Although the patients with Crohn's disease had reduced bone mineral density, the number of fractures were not different between the patient groups. However, the patients were relatively young, and prolonged disease and age related loss of bone mass could have a deleterious effect on the skeleton and further increase the fracture risk. If the difference in femoral neck bone mineral density of nearly one standard deviation persists during aging, it represents a $2 \cdot 6$-fold increased relative risk of hip fracture in patients with Crohn's disease. ${ }^{32}$

In summary, in a population based study we found reduced bone mineral density in a large proportion of patients with Crohn's disease, particularly in those who had used corticosteroids. This finding has therapeutic implications, and screening with bone mineral density measurement in this group of patients seems worthwhile. The use of corticosteroids is probably a major aetiological factor for bone loss in Crohn's disease although the total lifetime corticosteroid dose might reflect the activity and severity of the illness as well. As the bone mass in patients with ulcerative colitis was not different from that of healthy subjects, patients with Crohn's disease or ulcerative colitis should not be considered as a homogeneous group when skeletal effects of inflammatory bowel disease are studied.

1 Compston JE, Judd D, Crawley EO, Evans WD, Evans C, Church HA, et al. Osteoporosis in patients with inflammatory bowel disease. Gut 1987; 28: 410-5.

2 Pigot F, Roux C, Chaussade S, Hardelin D, Pelleter O, Du, et al. Low bone mineral density in patients with inflammatory bowel disease. Dig Dis Sci 1992; 37 1396-403.

3 Clements D, Motley RJ, Evans WD, Harries AD, Rhodes J, Coles RJ, et al. Longitudinal study of cortical bone loss in patients with inflammatory bowel disease. Scand $\mathcal{f}$ in patients with inflammatory

4 Bernstein CN, Seeger LL, Sayre JW, Anton PA, Artinian L, Shanahan F. Decreased bone density in inflammatory bowel disease is related to corticosteroid use and no disease diagnosis. F Bone Miner Res 1995; 10: 250-6.

5 Falch JA, Meyer HE. Bone mineral density measured by dual x-ray absorptiometry. Reference values in Norwegian population. Tidsskr Nor Laegeforen 1996; 116: 2299-302.

6 O'Neill TW, Felsenberg D, Varlow J, Cooper C, Kanis JA, Silman AJ, et al. The prevalence of vertebral deformity in European men and women: The European vertebral osteoporosis study. 7 Bone Miner Res 1996; 11: 1010-8.

7 Falch JA, Oftebro H, Haug E. Early postmenopausal bone loss is not associated with a decrease in circulating levels of 25-hydroxyvitanin D, or vitamin D-binding protein. $f$ Clin Endocrinol Metab 1987; 64: 836-41.
8 Scharla SH, Minne HW, Lempert UG, Leidig G, Hauber M, Raedsch $\mathrm{R}$, et al. Bone mineral density and calcium regulating hormones in patients with inflammatory bowel disease (Crohn's disease and ulcerative colitis). Exp Clin Endocrinol 1994; 102: 44-9.

9 Abitbol V, Roux C, Chaussade S, Guillemant S, Kolta S, Dougados M, et al. Metabolic bone assessment in patients with inflammatory bowel disease. Gastroenterology 1995 108: 417-22.

10 Silvennoinen JA, Karttunen TJ, Niemela SE, Manelius JJ, Lehtola JK. A controlled study on bone mineral density in patients with inflammatory bowel disease. Gut 1995; 37: 71-6.

11 Ghosh S, Cowen S, Hannan WJ, Ferguson A. Low bone mineral density in Crohn's disease, but not in ulcerative colitis, at diagnosis [comments]. Gastroenterology 1994; 107: 1031-9.

12 Lukert BP, Raisz LG. Glucocorticoid-induced osteoporosis [review]. Rheum Dis Clin North Am 1994; 20: 629-50.

13 Adler RA, Rosen CJ. Glucocorticoids and osteoporosis [review]. Endocrinol Metab Clin North Am 1994; 23: 641-54.

14 Reid IR, Evans MC, Stapleton J. Lateral spine densitometry is a more sensitive indicator of glucocorticoid-induced bone loss. F Bone Miner Res 1992; 7: 1221-5.

15 Gennari C. Glucocorticoids and bone. In: Peck WA, ed Bone and mineral research. Amsterdam: Elsevier Publishers BV, 1995: 213-32.

16 Reid IR, Evans MC, Wattie DJ, Ames R, Cundy TF. Bone mineral density of the proximal femur and lumbar spine in glucocorticoid-treated asthmatic patients. Osteoporos Int 1992; 2: 103-5.

17 Motley RJ, Crawley EO, Evans C, Rhodes J, Compston JE. Increased rate of spinal trabecular bone loss in patients with inflammatory bowel disease. Gut 1988; 29: 1332-6.

18 Roux C, Abitbol V, Chaussade S, Kolta S, Guillemant S, Dougados $M$, et al. Bone loss in patients with inflammatory bowel disease: a prospective study. Osteoporos Int 1995; 5: 156-60.

19 Nielsen HK, Charles P, Mosekilde L. The effect of single oral doses of prednisone on the circadian rhythm of serum osteocalcin in normal subjects. F Clin Endocrinol Metab 1988; 67: 1025-30

20 Poulijoki H, Liippo K, Herrala J, Salmi J, Tala E. Inhaled beclomethasone decreases serum osteocalcin in postmenopausal asthmatic women. Bone 1992; 13: 285-8.

21 MacDonald BR, Gowen M. Cytokines and bone [review] Brf Rheumatol 1992; 31: 149-55.

22 Bjarnason I, Macpherson A, Buxton-Thomas M, Forgacs I, Moniz C. High prevalence of osteoporosis in patients with inflammatory bowel disease and low lifetime intake of corticosteroids [abstract]. Gastroenterology 1993; 105: cortico

23 Vogelsang H, Ferenci P, Woloszczuk W, Resch H, Herold C, Frotz S, et al. Bone disease in vitamin D-deficient patients with Crohn's disease. Dig Dis Sci 1989; 34: 1094-9.

24 Tromm A, Rickels K, Huppe D, Wiebe V, May B. Osteopenia in chronic inflammatory bowel diseases. Results of a cross-sectional study using quantitative computerized tomography. Leber Magen Darm 1994; 24: 23-6. [In German.]

25 Edelstein SL, Barrett CE. Relation between body size and bone mineral density in elderly men and women. $A m \mathcal{F}$ Epidemiol 1993; 138: 160-9.

26 Felson DT, Zhang Y, Hannan MT, Anderson JJ. Effects of weight and body mass index on bone mineral density in men and women: the Framingham study. $\mathcal{F}$ Bone Miner Res 1993; 8: 567-73.

27 Ruegsegger P, Medici TC, Anliker M. Corticosteroidinduced bone loss. A longitudinal study of alternate day therapy in patients with bronchial asthma using quantitative computed tomography. Eur $f$ Clin Pharmacol 1983; 25: 615-20

28 Clements D, Compston JE, Evans WD, Rhodes J. Hormone replacement therapy prevents bone loss in patients with inflammatory bowel disease. Gut 1993; 34: 1543-6.

29 Hui SL, Slemenda CW, Johnston CJ. Baseline measurement of bone mass predicts fracture in white women. Ann Intern Med 1989; 111: 355-61.

30 Cummings SR, Black DM, Nevitt MC, Browner WS, Cauley JA, Genant HK, et al. Appendicular bone density and age predict hip fracture in women. The Study of Osteoporotic Fractures Research Group [comments]. Osteoporotic Fractures

31 Ross PD, Davis JW, Epstein RS, Wasnich RD. Pre-existing fractures and bone mass predict vertebral fracture incidence in women. Ann Intern Med 1991; 114: 919-23.

32 Cummings SR, Black DM, Nevitt MC, Browner W, Cauley J, Ensrud $\mathrm{K}$, et al. Bone density at various sites for prediction of hip fractures. The Study of Osteoporotic Fractures Research Group [comments]. Lancet 1993; 341: $72-5$. 